\title{
关于 $\mathrm{Na}_{2} \mathrm{O}-\mathrm{Al}_{2} \mathrm{O}_{3}-\mathrm{SiO}_{2}-\mathrm{H}_{2} \mathrm{O}$ 系的平衡固相
}

$\mathrm{Na}_{2} \mathrm{O}-\mathrm{Al}_{2} \mathrm{O}_{3}-\mathrm{SiO}_{2}-\mathrm{H}_{2} \mathrm{O}$ 系相图对铝冶 金、硅酸盐化学和热液成矿理论均有重要意 义. Деревякин 等研究 $\mathrm{Na}_{2} \mathrm{O}-\mathrm{Al}_{2} \mathrm{O}_{3}-\mathrm{SiO}_{2}-$ $\mathrm{H}_{2} \mathrm{O}$ 系水热条作下的平衡固相并发表了相 图 'II. 认为含氧化硅的铝酸钠 - 氢氧化钠 溶液析出的平衡固相主要是 “铝酸盐方钠 石” (Aluminate-Sodalite, $3\left[\mathrm{Na}_{2} \mathrm{O} \cdot \mathrm{Al}_{2} \mathrm{O}_{3}\right.$ - $\left.2 \mathrm{SiO}_{2} \mathrm{NaAl}(\mathrm{OH})_{4} \cdot \mathrm{H}_{2} \mathrm{O}\right)$ 和 “碱性方钠 石” (Basic Sodalite, $3\left[\mathrm{Na}_{2} \mathrm{O} \cdot \mathrm{Al}_{2} \mathrm{O}_{3} \cdot 2 \mathrm{SiO}_{2}\right]$ $\left.\mathrm{NaOH} \cdot \mathrm{H}_{2} \mathrm{O}\right)$, 并在相图中划分了二者各自 的初旵区。其中“碱性方钠石”实际上就是 沸石化学文献中在方钠石 $\beta$ 笼中嵌人 $\mathrm{NaOH}$ 的羟基方钠石 (Hydroxy-Sodalite). 它早已 见诸文献, 并为我们的实验验证。至于 “铝 酸盐方钠石”, 显然是 Деревякин 为了解释 低 $\mathrm{Na}_{2} \mathrm{O} / \mathrm{Al}_{2} \mathrm{O}_{3}$ 比的溶液析出的方钠石样品 $\mathrm{SiO}_{2} / \mathrm{Al}_{2} \mathrm{O}_{3}$ 比小于 2.0 (一般可达 $1.6 \sim 1.9$ ) 提出的. 西方国家若十沸石化学家在解释沸 石 $\mathrm{A}$ 样品有时富铝时, 也曾假设 $\mathrm{NaAlO}_{2}$ 嵌 人沸石 $\mathrm{A}$, 但这些假设并无唱体结构测定证 明. 何况方钠石 $\beta$ 笼内径仅 $0.33 \mathrm{~nm}$., 六元 环畕山半径仅 $0.22 \mathrm{~nm}$, 而 $\mathrm{Al}(\mathrm{OH})_{4}^{-}$描绘球 半径约 $0.33 \mathrm{~nm}$, 难于在 $\beta$ 笼中容纳和出 人, 故 “铝酸盐方钠石” 是否存在应进一步验 证. 为此, 我们取含 $\mathrm{Na}_{2} \mathrm{O} \quad 120 \mathrm{~g} / \mathrm{L}, \mathrm{Al}_{2} \mathrm{O}_{3}$ $115 \mathrm{~g} / \mathrm{L}, \mathrm{SiO}_{2} 3.5 \mathrm{~g} / \mathrm{L}$ 的过饱和溶液在 $150^{\circ} \mathrm{C}$ 高压釜中水热合成制取固相样品, 化 学分析表明其成分对应于 $1.02 \mathrm{Na}_{2} \mathrm{O} \cdot \mathrm{Al}_{2} \mathrm{O}_{3}$ - $1.75 \mathrm{SiO}_{2} \cdot 2 \mathrm{H}_{2} \mathrm{O}$. 作 X- 射线衍射和比
重、折光率测定, 证明为方钠石型唱体, 立方 晶系, 唱胞系数 $a=0.885 \mathrm{~nm}$, 比重 2.256, 折 光率 1.480 , 由此算出每个晶胞中 $\mathrm{Na}, \mathrm{Al}, \mathrm{Si}$, $\mathrm{H}, \mathrm{O}$ 原子的数目 (各晶胞平均值) 为: $\mathrm{Na}_{6} \mathrm{Al}_{6} \mathrm{Si}_{5.2} \mathrm{H}_{12} \mathrm{O}_{28.5}$, 而 Деревякин 提 出 $\left(\mathrm{Al}(\mathrm{OH})_{4}^{-}\right.$嵌人 $\beta$ 笼 $)$ 的 “铝酸盐方钠石” 唱胞 应含 $\mathrm{Na}_{7} \mathrm{Al}_{7} \mathrm{Si}_{6} \mathrm{H}_{6} \mathrm{O}_{29}$, 二者相差甚远. 可以看 出: 该样品 $\mathrm{SiO}_{2} / \mathrm{Al}_{2} \mathrm{O}_{3}$ 分子比小于 2.0 , 并不 是由于唱胞中 $\mathrm{Al}$ 原子增多, 而是由于 $\mathrm{Si}$ 原 子缺位. 可以想象, 从低 $\mathrm{Na}_{2} \mathrm{O} / \mathrm{Al}_{2} \mathrm{O}_{3}$ 溶液中 析出水化方钠石或羟基方钠石时, 由于局部 地区硅酸离子未能到达, 形成受 $\mathrm{Al}-\mathrm{O}-\mathrm{H}$ 包 围的 $\mathrm{Si}$ 空位, 是析出沉淀 $\mathrm{SiO}_{2} / \mathrm{Al}_{2} \mathrm{O}_{3}$ 小丁 2.0 的原因. 该样品折光率 (1.480) 亦较茨人 $\mathrm{NaOH}$ 的方钠石 (折光率 1.492) 为低, 显系 唱胞中原子数较小所致. 这一迹象也和嵌人 $\mathrm{Al}(\mathrm{OH})_{4}$ (其离子折射率应远大于 $\mathrm{OH}^{-}$) 的 假设有矛盾. 由此可见: Деревякин 等测定 的 $\mathrm{Na}_{2} \mathrm{O}-\mathrm{Al}_{2} \mathrm{O}_{3}-\mathrm{SiO}_{2}-\mathrm{H}_{2} \mathrm{O}$ 系相图这一部分 需要重新探讨.

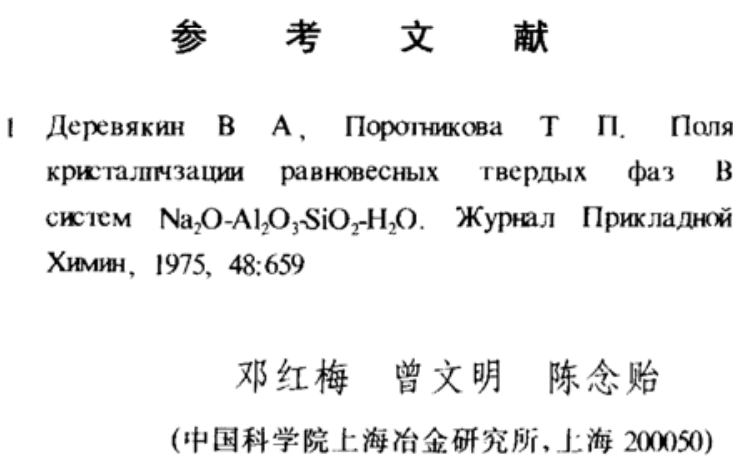

